\title{
To move or not to move?
}

\section{Semaphorin signalling in cell migration}

\author{
Luca Tamagnone+ \& Paolo M. Comoglio \\ University of Torino M edical School-IRCC, Candiolo, Italy
}

\begin{abstract}
Semaphorins were discovered 11 years ago as molecular cues for axon guidance that are conserved from invertebrates to humans. More than $\mathbf{2 0}$ semaphorin genes have been identified in mammals and their protein products are now known to be involved in a range of processes from the guidance of cell migration to the regulation of the immune response, angiogenesis and cancer. Plexins, either alone or in association with neuropilins, constitute highaffinity semaphorin receptors. However, other transmembrane molecules have been implicated in semaphorin receptor complexes, and interactions between plexins and a range of intracellular effectors have been reported. These data indicate that semaphorins might be able to elicit responses through more than one signalling pathway. Interestingly, according to recent findings, the semaphorin-dependent control of cell migration crucially involves integrin-based adhesive structures through which polarized cellmembrane protrusion is coupled to cytoskeletal dynamics. This review focuses on the mechanisms whereby semaphorins are thought to regulate cell migration.
\end{abstract}

Keywords: cancer; cell migration; integrins; plexin; semaphorin EM BO reports (2004) 5, 356-361. doi:10.1038/sj.embor.7400114

\section{Introduction}

Semaphorins are members of a large, highly conserved family of molecular signals that were identified initially through their role in axon guidance (Kolodkin et al, 1993; Luo et al, 1993), and later implicated in a range of functions from the guidance of cell migration and regulation of immune function, to angiogenesis and cancer (reviewed in Tamagnone \& Comoglio, 2000). More than 20 mammalian semaphorin proteins are known and they are divided into seven subclasses according to their structural features. Vertebrate semaphorins in subclass 3 are secreted and are thought to form steep tissue gradients. Several other semaphorins are associated with the cell surface, either as transmembrane proteins (subclasses 4, 5 and 6) or through glycosylphosphatidylinositol (GPI) linkage (subclass 7). Therefore, semaphorins can mediate both

University of Torino M edical School, Institutefor Cancer Research and Treatment, SP 142, 10060 Candiolo (Torino), Italy

+Corresponding author. Tel: +39 011 9933 204; Fax: +39 0119933 225;

E-mail: luca.tamagnone@ircc.it

Submitted 4 D ecember 2003; accepted 3 February 2004 long- and short-range (or contact-mediated) signals (Fig 1). Transmembrane semaphorins can also release a signalling-competent extracellular domain (Wang et al, 2001) or trigger 'reverse' signalling by functioning as receptors ( $\mathrm{Hall}$ et al, 1996; Godenschwege et al, 2002). Moreover, some migrating cells and axons express both receptors and ligands on the cell surface (Winberg et al, 1998), or secrete semaphorins in an autocrine fashion (for example, see Serini et al, 2003; Catalano et al, 2004).

In vitro and in vivo experiments have implicated semaphorins in the guidance of elongating axons and dendrites, as well as in axon branching, axon pruning (Bagri et al, 2003) and axon degeneration (for a review of neuronal functions, see $\mathrm{He}$ et al, 2002). Furthermore, semaphorins act as guidance cues for a range of migrating cells. For example, they control oligodendrocyte migration (Spassky et al, 2002) and are potentially involved in the glial ensheathment of axons (0 ster et al, 2003). The migration of neural crest cells is regulated by semaphorins (Eickholt et al, 1999), and defects in this process lead to the mispositioning of patterning cells in the sclerotome and in the developing cardiovascular system (Behar et al, 1996; Brown et al, 2001). Sema3A has a crucial role in regulating endothelial cell migration and angiogenesis ( $\mathrm{M}$ iao et al, 1999; Serini et al, 2003; Shoji et al, 2003), as well as in the topographic congruence of nerves and blood vessels (Bates et al, 2003). Moreover, semaphorins regulate epithelial cell migration and morphogenesis (Fujii et al, 2002; Ginzburg et al, 2002; Giordano et al, 2002), and leukocyte migration (D elaire et al, 2001).

Semaphorins have been mainly described as inhibitory signals because they prevent cell migration and axon outgrowth, and lead to the 'collapse' of both pseudopodia and axonal growth cones. However, it has been shown that semaphorins can sometimes promote cell chemotaxis, and axon/dendrite outgrowth and attraction (for example, see Polleux et al, 2000; Giordano et al, 2002; M oreno-Flores et al, 2003; Pasterkamp et al, 2003). These opposing functional responses might entail signalling pathways that are mediated by different semaphorin receptor complexes, as discussed below. Furthermore, there is evidence that semaphorin function can be modulated by the intracellular levels of cyclic nucleotides, which convert a repellent into an attractive cue (Song et al, 1998; Castellani et al, 2002). This indicates that semaphorin signalling can be steered in different directions depending on the cross-talk between their receptors and 
Secreted semaphorins

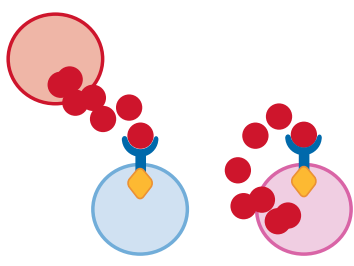

$.9 \uparrow_{\text {semanotomis }}$
GPI-linked semaphorins

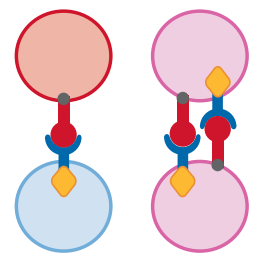

Transmembrane semaphorins

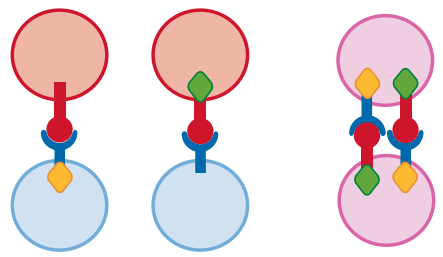

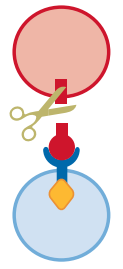

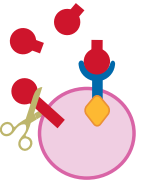

Semaphorins receptors (plexins)

Domain mediating forward signalling

Domain mediating reverse signalling

Fig1| Semaphorin signalling modes. Semaphorins and their receptorsmight be expressed on distinct cell populations (shown in red and blue, respectively) or be coexpressed ( pink). Secreted semaphorins mediate either paracrine or autocrinesignals. A part from classical forward signals, transmembrane semaphorins could also trigger reversesignalling (mediated by their cytoplasmic domain) or bereleased into the extracellular space by proteolytic cleavage and so behave as secreted ligands.

other pathways. In fact, functional antagonism between semaphorins and neurotrophic/mitogenic factors, such as nerve growth factor (N GF; Atwal et al, 2003), heregulin (HRG; Barberis et al, 2004) and stromal-cell-derived factor 1 (SDF1; Chalasani et al, 2003), has been reported.

\section{Semaphorin receptors and receptor complexes}

High-affinity receptors for semaphorins have been identified. They include the plexins, which are a family of large transmembrane molecules that are conserved from invertebrates to humans, and the neuropilins (NP1 and NP2) that are found only in vertebrates (Tamagnone \& Comoglio, 2000). Membrane-bound vertebrate semaphorins bind directly to plexins, whereas secreted semaphorins (class 3) also require neuropilins as obligate co-receptors. Several lines of evidence indicate that the cytoplasmic domain of plexins is required for semaphorin signalling, whereas the small cytosolic tail of neuropilins is dispensable. A recent study, however, revealed an independent functional role for the cytoplasmic tail of N P1, which is probably mediated through its PDZ (for PSD 95, Discs-large and ZO 1)-domain binding sequence (Wang et al, 2003).

Recently, two molecules that are unrelated to plexins or neuropilins, CD 72 and Tim2, were found to interact functionally (although at low affinity) with transmembrane semaphorins in the immune system (Kumanogoh et al, 2000, 2002). M oreover, although GPI-linked Sema7A is known to bind to plexin-C1 (Tamagnone et al, 1999), it also has plexin-independent activity that is mediated by integrin- $\beta 1$ (Pasterkamp et al, 2003).

Receptors on the plasma membrane often oligomerize in complexes, which allows for cross-talk between different signalling pathways. Semaphorin receptor complexes seem to be a good example of these interaction centres (Fig 2). In fact, as well as plexins and neuropilins, other transmembrane molecules are functionally coupled to semaphorin receptors, including celladhesion molecule L1 (Castellani et al, 2002), and the receptortype tyrosine kinases off-track kinase (OTK; Winberg et al, 2001) and the hepatocyte growth-factor/scatter-factor receptor Met (Giordano et al, 2002). For instance, in cells that express a complex of plexin-B1 and Met, Sema4D can trigger Met activation and intracellular signalling (Giordano et al, 2002). This leads to a programme known as 'invasive growth', which is implicated in a range of morphogenetic processes from neurite outgrowth to branched tubulogenesis of epithelia, as well as in cancer invasion and metastasis (Trusolino \& Comoglio, 2002). Furthermore, recent data show that other plexins of the $B$ subfamily specifically associate with the scatter-factor receptors $M$ et and Ron (Conrotto et al, 2004). Importantly, evidence indicates that semaphorins can induce different functional responses, depending on the signalling molecules that are found in the receptor complex. For example, Sema4D can mediate attraction through M et activation, whereas it inhibits cell adhesion and cell migration through plexin-specific and Met-independent signalling (Barberis et al, 2004). By analogy, Kikutani and co-workers have recently shown that, in response to its newly identified ligand Sema6D, plexin-A1 can alternatively mediate attractive or repellent cues in different cell populations, depending on its association with tyrosine kinase receptors of vascular endothelial grow th factors (VEG Fs) or with OTK (Toshihiko et al, 2004).

Neuropilins, in addition to binding secreted semaphorins, are also VEG F co-receptors (Soker et al, 1998; Gluzman-Poltorak et al, 2001) and are crucially required for vascular development (Kawasaki et al, 1999; Takashima et al, 2002). H owever, the mechanisms by which neuropilins switch between semaphorin and VEGF signalling are unclear. It has been shown that Sema3A competes with VEG F165 for binding to NP1 and that it inhibits VEG F-mediated function in endothelial cells (M iao et al, 1999), although recent data challenge the relevance of this regulation in vivo ( $G$ u et al, 2003). Conversely, several experiments indicate that plexins have an important role in the functional response to secreted semaphorins in endothelial, epithelial and mesothelial cells (Bachelder et al, 2003; Serini et al, 2003; Catalano et al, 2004), which suggests that secreted semaphorins are more likely to regulate cell migration and angiogenesis through plexin-specific signalling than by inhibiting VEGF-receptor activation.

\section{Mechanisms of semaphorin-mediated cell guidance}

Semaphorins guide both axonal extension and cell migration. There are notable similarities (and some peculiarities) between the leading edge of a migrating cell and that of an extending axon, or the 'grow th cone' (D ent \& Gertler, 2003). We focus on the molecular mechanisms that are thought to mediate plexin function in cell migration. This is a complex process that is regulated at many levels (Ridley et al, 2003). To migrate, a cell must free its tethers to 


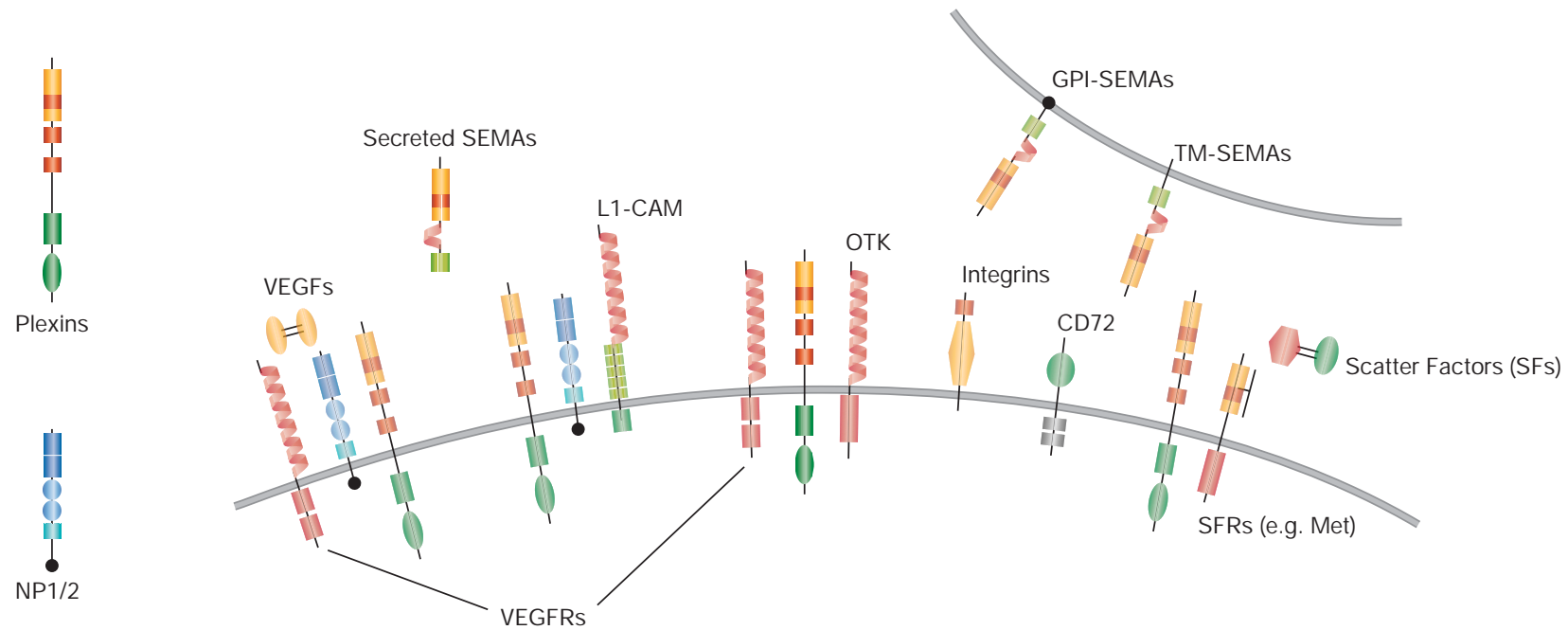

Fig2 | Semaphorin receptor complexes. Plexins bind semaphorins (SEM As) and can form receptor complexes with neuropilins 1 and 2 (N P1/2), with celladhesion molecule L1 (L1-CAM) and with receptor tyrosinekinases, such as off-track kinase (OTK), scatter-factor receptors (SFRs) and vascular endothelial growth factor receptors (VEGFRs). N europilins act as co-receptors for both secreted semaphorins and VEGFs. Integrins are receptors of extracellular matrix components, but integrin- $\beta 1$ also mediates Sema7A activity. CD 72 is a low affinity receptor for Sema4D. GPI, glycosylphosphatidylinositol; TM , transmembrane.

the extracellular matrix and sometimes to neighbouring cells (such as in epithelia). It must then form polarized cellular protrusions (filopodia and lamellipodia), which requires actin polymerization and new transient adhesive structures on the leading edge. According to the prevailing view, these focal complexes are privileged sites for Rac signalling and the polymerization of an actin meshwork, which pushes forward the leading edge so that it invades the surrounding tissue (Fig 3). Conversely, rear-edge retraction and cell-body translocation require myosin-mediated pulling on F-actin cables, which are anchored to stabilized focal adhesions behind the leading edge. This mechanism is triggered by Rho and Rho-dependent kinase (ROCK). Importantly, during cell migration, leading protrusions might retract owing to repelling signals or to the absence of permissive adhesive substrates and chemoattractant cues. Moreover, the absence of survival factors can abort cell migration via apoptosis. Intriguingly, semaphorins have been shown to mediate cell-to-cell repulsion, regulate cell-substrate adhesion and actin polymerization, induce retraction of cellular processes (a process often termed 'cellular collapse') and elicit cell apoptosis.

Although plexins must have a role in mediating these effects, the signalling mechanisms that are triggered by the large conserved cytoplasmic domain of these receptors are poorly understood. In fact, this sequence is not notably related to any other found in the databases and, although it bears limited similarity to GTPase-activating proteins (Rohm et al, 2000), there has been no report of any catalytic activity that is intrinsic to plexins. During the past two years, several potential semaphorin signal transducers have been identified on the basis of their association with plexins (for a review, see Pasterkamp $\&$ Kolodkin, 2003). However, the specific role of these molecules in semaphorin-mediated functions is still unclear.

The small GTPases of the Rho family are well-known regulators of cytoskeletal dynamics, cell migration and axon guidance, and several reports indicate that they have a role in semaphorin function. For example, plexins of the B subfamily can associate with GTP/GDP exchange molecules or Rho-GEFs, and induce Rho activation (for example, see Perrot et al, 2002; Swiercz et al, 2002). H owever, the functional role of the effector molecule ROCK in semaphorin signalling is debated (for example, see Jin \& Strittmatter, 1997; Swiercz et al, 2002; O inuma et al, 2003; Barberis et al, 2004).

M oreover, human plexin-B1 and fly plexin $B$, but not other family members, interact with activated Rac (Vikis et al, 2000; D riessens et al, 2001). It was suggested that these plexins sequester activated Rac and antagonize its signalling pathway ( $\mathrm{Hu}$ et al, 2001; Vikis et al, 2002). However, other evidence indicates that Rac activity is required for semaphorin function, and possibly mediates actin rearrangement, membrane transport and endocytosis (Jin \& Strittmatter, 1997; Fournier et al, 2000; Jurney et al, 2002; Vikis et al, 2002). Taken together, it seems that the available evidence does not reach a consensus on the mechanisms whereby Rho GTPases could mediate plexin signalling, and further experiments are required to more fully determine their role as regulators of semaphorin functions.

Two recent reports have shown that semaphorins and plexins regulate integrin function in cell-substrate adhesion and cell migration (Serini et al, 2003; Barberis et al, 2004). Serini and colleagues showed that Sema3A inhibits the adhesion of endothelial cells to the extracellular matrix (ECM) and impedes their directional motility, which could explain the aberrant vascularization that is observed in Sema3A-deficient mice. Moreover, we have shown that plexin signalling negatively regulates integrin-based adhesive complexes, which leads to the inhibition of substrate adhesion, lamellipodia extension and cell migration (Barberis et al, 2004). This study also indicates that the plexin-mediated disassembly of adhesive structures is responsible for the typical collapsing response that is observed in vitro.

Semaphorins, plexins and scatter-factor receptors all contain a sema domain, which is a conserved sequence of approximately 500 amino acids. Intriguingly, this domain and the extracellular domain of $\alpha$-integrins have a similar structural motif, the 


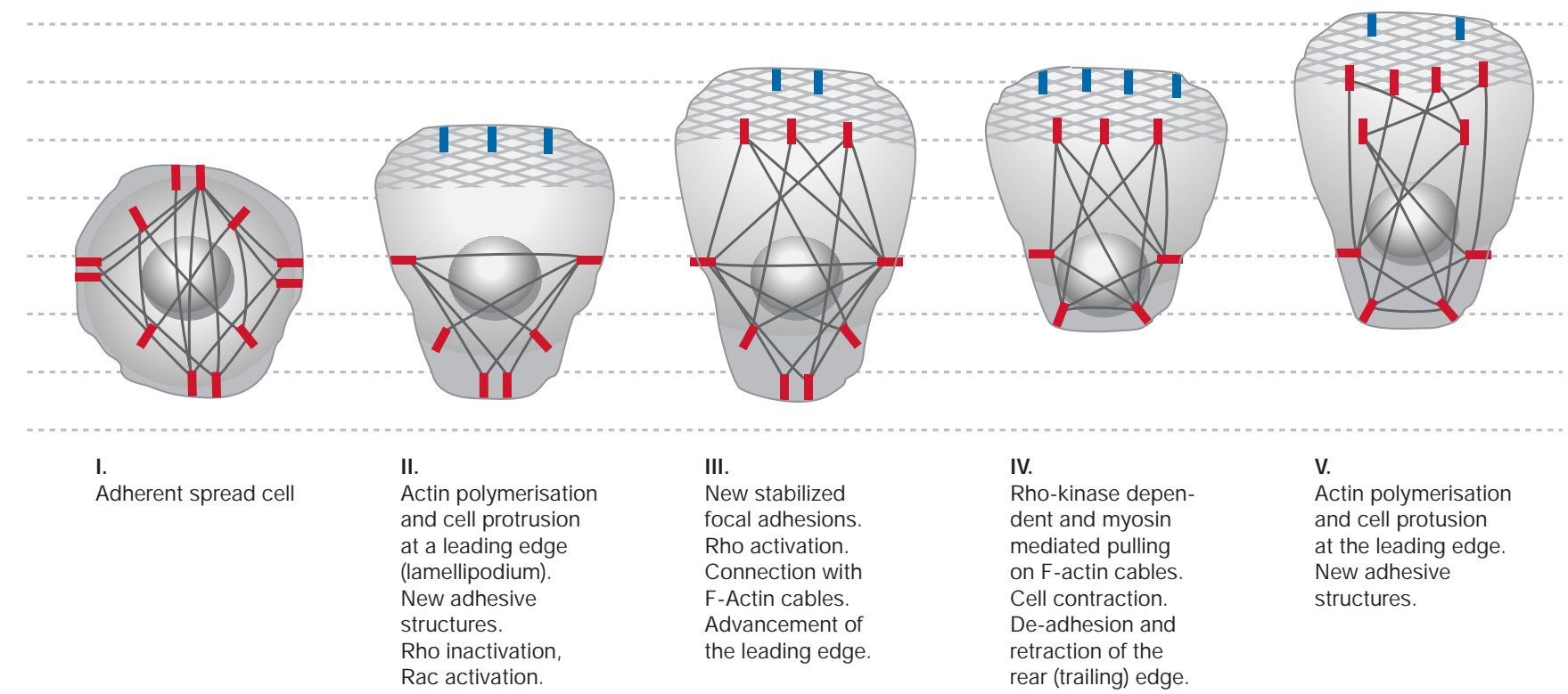

Fig3|Actin cytoskeleton and focal adhesivestructures in lamellipodia extension and cell locomotion. F-actin cables are shown in black. Stabilized focal adhesions are indicated by red bars. The patterned areas at the leading edgeindicatethemembrane pushing actin meshwork. Bluebars indicatenewly formed transient focal complexes. Theadvancement of theleading edge correlates with thematuration of focal complexes into stabilized structures that areconnected to F-actin cables.

$\beta$-propeller module, which is thought to act as a homo- and heterodimerization motif (Antipenko et al, 2003; G herardi et al, 2003; Love et al, 2003). In addition, all sema domains are flanked by short, conserved cysteine-rich motifs (the Met-related sequence (MRS), also known as the plexin-semaphorin-integrin (PSI) domain) that are similar to sequences found in the extracellular domain of $\beta$-integrins (Bork et al, 1999). Until now, a direct interaction between integrins and plexins has not been reported, although their structural similarity could reflect the phylogenetic conservation of functional domains. For example, the extracellular domain of integrins is flexed in the inhibited conformation and straight in the active conformation. By analogy, it is proposed that the sema domain of plexins acts as an inhibitory moiety by steric hindrance, which is displaced on ligand binding (Takahashi $\&$ Strittmatter, 2001; Antipenko et al, 2003).

Furthermore, as mentioned earlier, the GPI-anchored semaphorin Sema7A activates integrin- $\beta 1$ and mitogen-activated protein kinase (MAPK) signalling in a plexin-independent manner (Pasterkamp et al, 2003). This indicates that semaphorins can regulate integrin-mediated adhesion by at least two distinct mechanisms.

It is known that cell migration is inhibited by both lack of adhesion and the presence of stiff non-dynamic adhesive structures (Webb et al, 2002). In fact, signals that release cell-substrate adhesion are normally required to start cell migration, whereas sustained inhibition of integrin function blocks cell motility and eventually leads to the passive retraction of pseudopodia. By impinging on this delicate balance, semaphorins could potentially act both as permissive and as inhibitory cues for lamellipodia extension and cell migration. Moreover, as integrin signalling is required for cell survival and proliferation (Stupack \& Cheresh, 2002), its sustained inhibition might account for the reduced growth and apoptotic events that are observed in semaphorin-treated cells (for example, see Tomizawa et al, 2001).

\section{Semaphorins and cancer}

The involvement of semaphorins in cancer progression is suggested by several reports. For example, the overexpression of secreted semaphorins Sema3E and Sema3C is associated with the invasive and metastatic behaviour of tumour cells (Yamada et al, 1997; Christensen et al, 1998). However, Sema3B and Sema3F are putative oncosuppressor genes that undergo gene deletion or promoter hypermethylation in human tumours (Tomizawa et al, 2001; Xiang et al, 2002; Kuroki et al, 2003). The mechanisms that mediate these opposing effects are largely unknown at present. They could depend on both cell-autonomous effects on tumour cell motility and cell survival, and on the paracrine regulation of the tumour environment, for example, neo-angiogenesis and leukocyte chemotaxis. As discussed above, secreted semaphorins might negatively regulate VEGF-receptor-mediated signalling by sequestering the shared neuropilin co-receptors or they could trigger plexin signalling to regulate cell adhesion and cell migration, and potentially induce apoptosis. For example, Sema3A inhibits endothelial cell migration and tumour cell growth in vitro in a neuropilin- and plexin-dependent manner (Serini et al, 2003; Catalano et al, 2004). In addition, recent studies have shown thatVEGF can act as a survival and chemotactic factor for cancer cells in a VEGF-receptor-independent manner, probably by antagonizing the activity of semaphorins that is mediated by neuropilin/plexin complexes (Bachelder et al, 2003).

Conversely, membrane-bound semaphorin Sema4D (which is unable to bind neuropilins) can trigger the activation of the oncogenic receptor $M$ et, which is associated with plexin-B1 on the cell surface. This confirms that semaphorins can regulate cancer progression both positively and negatively through distinctive pathways. Future studies will be required to elucidate the network of these molecular mechanisms, and to define whether specific semaphorins and semaphorin receptors should be regarded as promoters or suppressors of cancer progression. 


\section{Conclusions and future perspectives}

$\mathrm{O}$ ur understanding of the signalling pathways that are elicited by semaphorins is still incomplete. G TPases of the Rho family are candidate signal transducers of the plexins; however, evidence of the direct mechanisms through which they are involved is lacking. Recent findings indicate that plexin signalling regulates integrin-based adhesion, al though the molecular mechanisms still need to be defined.

A few years ago, we proposed that semaphorins could guide cell migration through 'stop or go' signals in addition to their role in axon guidance. So far, we know that, by modulating integrin function and cytoskeletal dynamics in a site-specific manner, plexins can guide directional lamellipodia extension and cell motility. Moreover, recent evidence shows that plexins can couple to many other cellsurface signalling molecules. A better understanding of the mechanisms that regulate these interactions could be key to explaining the spectrum of functional responses that are mediated by semaphorins in different cells and tissues, including the control of such complex processes as tubular morphogenesis, angiogenesis, the immune response and the invasive growth of cancers.

\section{ACKN O W LED GEMENTS}

Wethank S. Giordano and A. Kolodkin for useful comments and suggestions on the manuscript. Weapologizeto our colleagues whoseimportant studies have not been cited owing to space limitations. Work in theauthors' laboratories is supported by the Italian Association for Cancer Research, the EM BO Young Investigator Programme(LT) and the Italian M inistry for Education, Higher Education and Research.

\section{REFEREN CES}

Antipenko A et al (2003) Structure of the semaphorin-3A receptor binding module. Neuron 39: 589-598

Atwal JK, Singh KK, Tessier-Lavigne M, Miller FD, Kaplan DR (2003) Semaphorin $3 \mathrm{~F}$ antagonizes neurotrophin-induced phosphatidylinositol 3-kinase and mitogen-activated protein kinase kinase signaling: a mechanism for grow th cone collapse. J N eurosci 23: 7602-7609

Bachelder RE, Lipscomb EA, Lin X, Wendt M A, Chadborn NH, Eickholt BJ, Mercurio AM (2003) Competing autocrine pathways involving alternative neuropilin-1 ligands regulate chemotaxis of carcinoma cells. Cancer Res 63: 5230-5233

Bagri A, Cheng HJ, Yaron A, Pleasure SJ, Tessier-Lavigne M (2003) Stereotyped pruning of long hippocampal axon branches triggered by retraction inducers of the semaphorin family. Cell 113: 285-299

Barberis D, Artigiani S, Casazza A, Corso S, Giordano S, Love CA, Jones EY, Comoglio PM, Tamagnone L (2004) Plexin signaling hampers integrinbased adhesion, leading to Rho-kinase independent cell rounding, and inhibiting lamellipodia extension and cell motility. FASEB J 18: 592-594

Bates D, Taylor GI, Minichiello J, Farlie P, Cichowitz A, Watson N, Klagsbrun M, M amluk R, N ew green DF (2003) N eurovascular congruence results from a shared patterning mechanism that utilizes Semaphorin3A and Neuropilin-1. D ev Biol 255: 77-98

Behar O, Golden JA, M ashimo H, Schoen FJ, Fishman MC (1996) Semaphorin III is needed for normal patterning and growth of nerves, bones and heart. Nature 383: 525-528

Bork P, D oerks T, Springer TA, Snel B (1999) D omains in plexins: links to integrins and transcription factors. Trends Biochem Sci 24: 261-263

Brown CB, Feiner L, Lu M M , Li J, M a X, Webber AL, Jia L, Raper JA, Epstein JA (2001) PlexinA2 and semaphorin signaling during cardiac neural crest development. Development 128: 3071-3080

Castellani V, De Angelis E, Kenwrick S, Rougon G (2002) Cis and trans interactions of $\mathrm{L} 1$ with neuropilin-1 control axonal responses to semaphorin 3A. EM BO J 21: 6348-6357

Catalano A, Caprari P, Rodilossi S, Betta P, Castellucci M, Casazza A, Tamagnone L, Procopio A (2004) Cross-talk between vascular endothelial growth factor and semaphorin-3A pathway in the regulation of normal and malignant mesothelial cell proliferation. FASEB J 18: 358-360
Chalasani SH, Sabelko KA, Sunshine MJ, Littman DR, Raper JA (2003) A chemokine, SD F-1, reduces the effectiveness of multiple axonal repellents and is required for normal axon pathfinding. J N eurosci 23: 1360-1371

Christensen CR, Klingelhofer J, Tarabykina S, Hulgaard EF, Kramerov D, Lukanidin E (1998)Transcription of a novel mouse semaphorin gene, $\mathrm{M}$-semaH , correlates with the metastatic ability of mouse tumor cell lines. Cancer Res 58: 1238-1244

Conrotto P, Corso S, Gamberini S, Comoglio PM , Giordano S (2004) Interplay between scatter factor receptors and B plexins controls invasive growth. Oncogene (in press)

Delaire S, Billard C, Tordjman R, Chedotal A, Elhabazi A, Bensussan A, Boumsell L (2001) Biological activity of soluble CD 100. II. Soluble $\mathrm{CD} 100$, similarly to $\mathrm{H}$-Semalll, inhibits immune cell migration. J Immunol 166: 4348-4354

Dent EW, G ertler FB (2003) Cytoskeletal dynamics and transport in grow th cone motility and axon guidance. N euron 40: 209-227

D riessens M H, Hu H, Nobes CD, Self A, Jordens I, Goodman CS, Hall A (2001) Plexin-B semaphorin receptors interact directly with active Rac and regulate the actin cytoskeleton by activating Rho. Curr Biol 11: 339-344

Eickholt BJ, M ackenzie SL, Graham A, Walsh FS, D oherty P (1999) Evidence for collapsin-1 functioning in the control of neural crest migration in both trunk and hindbrain regions. Development 126: 2181-2189

Fournier AE, N akamura F, Kawamoto S, G oshima Y, Kalb RG, Strittmatter SM (2000) Semaphorin3A enhances endocytosis at sites of receptor-F-actin colocalization during growth cone collapse. J Cell Biol 149: 411-422

Fujii T, N akao F, Shibata Y, Shioi G, Kodama E, Fujisawa H, Takagi S (2002) Caenorhabditis elegans PlexinA, PLX-1, interacts with transmembrane semaphorins and regulates epidermal morphogenesis. Development 129, 2053-2063

Gherardi E, Youles ME, Miguel RN, Blundell TL, lamele L, Gough J, Bandyopadhyay A, H artmann G, Butler PJ (2003) Functional map and domain structure of $\mathrm{MET}$, the product of the c-met protooncogene and receptor for hepatocyte grow th factor/scatter factor. Proc N atl Acad Sci USA 100: 12039-12044

GinzburgVE, Roy PJ, Culotti JG (2002) Semaphorin la and semaphorin 1b are required for correct epidermal cell positioning and adhesion during morphogenesis in C. elegans. Development 129: 2065-2078

Giordano S, Corso S, Conrotto P, Artigiani S, Gilestro G, Barberis D, Tamagnone L, Comoglio PM (2002)The semaphorin 4D receptor controls invasive growth by coupling with $\mathrm{M}$ et. N at Cell Biol 4: 720-724

Gluzman-Poltorak Z, Cohen T, Shibuya M, N eufeld G (2001)Vascular endothelial growth factor receptor-1 and neuropilin-2 form complexes. J Biol Chem 276: 18688-18694

Godenschwege TA, Hu H, Shan-Crofts X, Goodman CS, M urphey RK (2002) Bi-directional signaling by Semaphorin 1a during central synapse formation in D rosophila. $N$ at $N$ eurosci $5,1294-1301$

Gu C, Rodriguez ER, Reimert DV, Shu T, Fritzsch B, Richards LJ, Kolodkin AL, Ginty DD (2003) N europilin-1 conveys semaphorin and VEG F signaling during neural and cardiovascular development. Dev Cell 5: 45-57

Hall KT, Boumsell L, Schultze JL, BoussiotisVA, D orfman DM, Cardoso AA, Bensussan A, N adler LM, Freeman GJ (1996) Human CD 100, a novel leukocyte semaphorin that promotes B-cell aggregation and differentiation. Proc Natl Acad Sci U SA 93: 11780-11785

He Z, Wang KC, Koprivica V, Ming G, Song HJ (2002) Knowing how to navigate: mechanisms of semaphorin signaling in the nervous system. Sci STKE 2002: RE1

Hu H, M arton TF, Goodman CS (2001) Plexin B mediates axon guidance in D rosophila by simultaneously inhibiting active Rac and enhancing RhoA signaling. Neuron 32: 39-51

Jin Z, Strittmatter SM (1997) Rac1 mediates collapsin-1-induced growth cone collapse. J N eurosci 17: 6256-6263

Jurney W M , Gallo G, Letourneau PC, M CLoon SC (2002) Rac1-mediated endocytosis during ephrin-A2-and semaphorin 3A-induced growth cone collapse. J N eurosci 22: 6019-6028

Kawasaki T, Kitsukawa T, BekkuY, M atsudaY, Sanbo M, Yagi T, Fujisawa H (1999) A requirement for neuropilin-1 in embryonic vessel formation. Development 126: 4895-4902 
Kolodkin AL, M atthes DJ, Goodman CS (1993) The semaphorin genes encode a family of transmembrane and secreted growth cone guidance molecules. Cell 75: 1389-1399

Kumanogoh A et al (2000) Identification of CD 72 as a lymphocyte receptor for the class IV semaphorin CD 100: a novel mechanism for regulating $B$ cell signaling. Immunity 13: 621-631

Kumanogoh A et al (2002) Class IV semaphorin Sema4A enhances T-cell activation and interacts with Tim-2. N ature 419: 629-633

Kuroki T, Trapasso F, Yendamuri S, M atsuyama A, Alder H, W illiams N N, Kaiser LR, Croce CM (2003) Allelic loss on chromosome 3p21.3 and promoter hypermethylation of semaphorin $3 \mathrm{~B}$ in non-small cell lung cancer. Cancer Res 63: 3352-3355

Love CA, H arlos K, M avaddat N, D avis SJ, Stuart DI, Jones EY, Esnouf RM (2003) The ligand-binding face of the semaphorins revealed by the high-resolution crystal structure of SEM A4D. N at Struct Biol 10: 843-848

Luo Y, Raible D, Raper JA (1993) Collapsin: a protein in brain that induces the collapse and paralysis of neuronal growth cones. Cell 75: 217-227

Miao H Q, Soker S, Feiner L, Alonso JL, Raper JA, Klagsbrun M (1999) N europilin-1 mediates collapsin-1/semaphorin III inhibition of endothelial cell motility: functional competition of collapsin-1 and vascular endothelial growth factor-165. J Cell Biol 146: 233-242

Moreno-Flores M T, M artin-A paricio E, M artin-Bermejo MJ, Agudo M, McM ahon S, Avila J, Diaz-N ido J, Wandosell F (2003) Semaphorin 3C preserves survival and induces neuritogenesis of cerebellar granule neurons in culture. J N eurochem 87: 879-890

O inuma I, Katoh H, Harada A, N egishi M (2003) Direct interaction of Rnd1 with Plexin-B1 regulates PDZ-RhoG EF-mediated Rho activation by Plexin-B1 and induces cell contraction in COS-7 cells. J Biol Chem 278: 25671-25677

O ster SF, Bodeker M O, He F, Sretavan DW (2003) Invariant Sema5A inhibition serves an ensheathing function during optic nerve development. Development 130: 775-784

Pasterkamp RJ, Kolodkin AL (2003) Semaphorin junction: making tracks toward neural connectivity. Curr O pin N eurobiol 13: 79-89

Pasterkamp RJ, Peschon JJ, Spriggs MK, Kolodkin AL (2003) Semaphorin 7A promotes axon outgrow th through integrins and MAPKs. N ature 424: 398-405

PerrotV, Vazquez-Prado J, Gutkind JS (2002) Plexin B regulates Rho through the guanine nucleotide exchange factors leukemia-associated Rho GEF (LARG) and PDZ-RhoGEF. J Biol Chem 277: 43115-43120

Polleux F, M orrow T, G hosh A (2000) Semaphorin 3A is a chemoattractant for cortical apical dendrites. N ature 404: 567-573

Ridley AJ, Schwartz MA, Burridge K, Firtel RA, Ginsberg M H, Borisy G, Parsons JT, H orwitz AR (2003) Cell migration: integrating signals from front to back. Science 302: 1704-1709

Rohm B, Rahim B, Kleiber B, H ovatta I, Puschel AW (2000)The semaphorin $3 A$ receptor may directly regulate the activity of small GTPases. FEBS Lett 486: $68-72$

Serini G et al (2003) Class 3 semaphorins control vascular morphogenesis by inhibiting integrin function. N ature 424: 391-397

Shoji W, Isogai S, Sato-M aeda M, O binata M, Kuwada JY (2003) Semaphorin3a1 regulates angioblast migration and vascular development in zebrafish embryos. Development 130: 3227-3236

Soker S, Takashima S, Miao HQ, N eufeld G, Klagsbrun M (1998) N europilin-1 is expressed by endothelial and tumor cells as an isoform-specific receptor for vascular endothelial growth factor. Cell 92: 735-745

Song H, Ming G, He Z, Lehmann M, M cKerracher L, Tessier-Lavigne M, Poo M (1998) Conversion of neuronal grow th cone responses from repulsion to attraction by cyclic nucleotides. Science 281: 1515-1518

Spassky N, de Castro F, Le Bras B, Heydon K, Q ueraud-LeSaux F, Bloch-Gallego E, Chedotal A, Zalc B, Thomas JL (2002) Directional guidance of oligodendroglial migration by class 3 semaphorins and netrin-1. J N eurosci 22: 5992-6004

Stupack DG, Cheresh DA (2002) G et a ligand, get a life: integrins, signaling and cell survival. J Cell Sci 115: 3729-3738
Swiercz JM, Kuner R, Behrens J, O ffermanns S (2002) Plexin-B1 directly interacts with PDZ-RhoG EF/LARG to regulate RhoA and grow th cone morphology. N euron 35: 51-63

Takahashi T, Strittmatter SM (2001) Plexinal autoinhibition by the plexin sema domain. Neuron 29: 429-439

Takashima S et al (2002) Targeting of both mouse neuropilin-1 and neuropilin2 genes severely impairs developmental yolk sac and embryonic angiogenesis. Proc N atl Acad Sci U SA 99: 3657-3662

Tamagnone $L$ et al (1999) Plexins are a large family of receptors for transmembrane, secreted, and G PI-anchored semaphorins in vertebrates. Cell 99: 71-80

Tamagnone L, Comoglio PM (2000) Signalling by semaphorin receptors: cell guidance and beyond. Trends Cell Biol 10: 377-383

TomizawaY, Sekido Y, Kondo M, Gao B, Yokota J, Roche J, D rabkin H, Lerman MI, Gazdar AF, M inna JD (2001) Inhibition of lung cancer cell growth and induction of apoptosis after reexpression of 3p21.3 candidate tumor suppressor gene SEM A3B. Proc N atl Acad Sci U SA 98: 13954-13959

Toshihiko T et al (2004) Dual roles of Sema6D in cardiac morphogenesis through region-specific association of its receptor, Plexin-A1, with 0 ffTrack and vascular endothelial growth factor receptor type 2. G enes D ev 18 (in press)

Trusolino L, Comoglio PM (2002) Scatter-factor and semaphorin receptors: cell signalling for invasive growth. N at Rev Cancer 2: 289-300

Vikis HG, Li W, Guan KL (2002)The plexin-B1/Rac interaction inhibits PAK activation and enhances Sema4D ligand binding. Genes Dev 16: 836-845

Vikis HG , Li W, He Z, Guan KL (2000)The semaphorin receptor plexin-B1 specifically interacts with active Rac in a ligand-dependent manner. Proc Natl Acad Sci USA 97: 12457-12462

Wang L, Zeng H, Wang P, Soker S, M ukhopadhyay D (2003) N europilin-1mediated vascular permeability factor/vascular endothelial grow th factordependent endothelial cell migration. J Biol Chem 278: 48848-48860

Wang X, Kumanogoh A, Watanabe C, Shi W, Yoshida K, Kikutani H (2001) Functional soluble CD 100/Sema4D released from activated lymphocytes: possible role in normal and pathologic immune responses. Blood 97: 3498-3504

Webb DJ, Parsons JT, H orwitz AF (2002) Adhesion assembly, disassembly and turnover in migrating cells- over and over and over again. $\mathrm{N}$ at Cell Biol 4: E97-E100

W inberg M L, N oordermeer JN, Tamagnone L, Comoglio PM, Spriggs MK, Tessier-Lavigne M, Goodman CS (1998) Plexin A is a neuronal semaphorin receptor that controls axon guidance. Cell 95: 903-916

Winberg M L, Tamagnone L, Bai J, Comoglio PM, M ontell D, Goodman CS (2001) The transmembrane protein O ff-track associates with plexins and functions downstream of semaphorin signaling during axon guidance. Neuron 32: 53-62

Xiang R, Davalos AR, Hensel CH, Zhou XJ, Tse C, N aylor SL (2002) Semaphorin 3F gene from human 3p21.3 suppresses tumor formation in nude mice. Cancer Res 62: 2637-2643

Yamada T, Endo R, G otoh M, Hirohashi S (1997) Identification of semaphorin $E$ as a non-M DR drug resistance gene of human cancers. Proc N atl Acad Sci U SA 94: 14713-14718

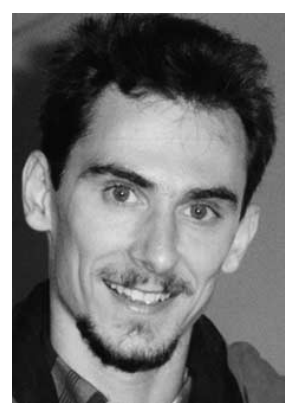

Luca Tamagnone

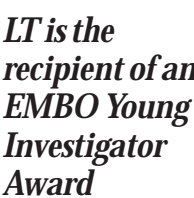

Award

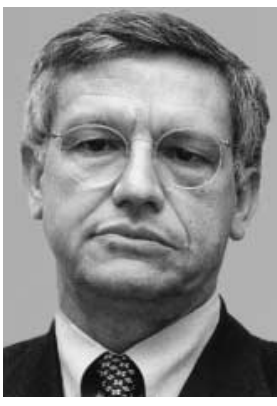

Paolo M. Comoglio 